\title{
A facile recycling and regeneration process for spent $\mathrm{LiFePO}_{4}$ batteries
}

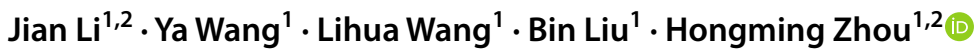

Received: 23 May 2019 / Accepted: 4 July 2019 / Published online: 29 July 2019

(c) The Author(s) 2019

\begin{abstract}
In response to the potential environment pollution and energy waste caused by the increasing spent lithium iron phosphate batteries (LFPs), many recycling methods have been developed. Among previous studies, the physical recycling method has attracted numerous attention due to its uncomplicated process and high efficiency. This work provides a regeneration mechanism of that the organic carbon layer is in situ coated on the surface of $\mathrm{LiFePO}_{4}$ particles by the decomposition of binder so that improves the conductivity and rate capability. When serving as cathode material for lithium ion battery, the $3 \mathrm{~h}$-regenerated lithium iron phosphate battery delivers an excellent electrochemical performance which shows a discharge specific capacity of $151.55 \mathrm{mAh} \mathrm{g}^{-1}$ at $0.2 \mathrm{C}$ and delivers a discharge capacity of $120.44 \mathrm{mAh} \mathrm{g}^{-1}$ even at $10 \mathrm{C}$ compared with pristine spent LFPs. It delivers a discharge capacity of $124.35 \mathrm{mAh} \mathrm{g}^{-1}$ in first cycle and maintains $103.12 \mathrm{mAh} \mathrm{g}^{-1}$ with a high capacity retention rate of $82.93 \%$ after 2000 cycles at $0.5 \mathrm{C}$ through 18,650 battery testing. Meaningfully, a facile and sustainable regeneration process has been demonstrated to re-synthesize $\mathrm{LiFePO}_{4}$ from spent LFPs by our study which can be reused as cathode materials for lithium-ion batteries, indicating an economical and facile method to recycle spent $\mathrm{LiFePO}_{4}$ materials in large scale.
\end{abstract}

\section{Introduction}

Lithium iron phosphate $\left(\mathrm{LiFePO}_{4}, \mathrm{LFP}\right)$ batteries are widely used in electric vehicles (EVs) and hybrid electric vehicles (HEVs) due to its long term cycle performance and high security in recent years [1-3]. In general, the original structure and content of the electrode material changes and results in capacity fading after using for a long time. Considering the more $\mathrm{LiFePO}_{4}$ batteries used in the market of EVs and HEVs, meaning the more spent batteries. The recovery and reuse of key components in $\mathrm{LiFePO}_{4} / \mathrm{C}$ batteries and the spent $\mathrm{LiFePO}_{4} / \mathrm{C}$ batteries have attracted widely attention $[4,5]$. Therefore, it is urgent to develop an efficient way to reuse spent $\mathrm{LiFePO}_{4}$ cathode materials for the potential environmental protection and energy waste issues.

Conventional recycling methods frequently recovering precious metals from spent cathode materials and then reusing them on the cathode materials such as $\mathrm{LiCoO}_{2}, \mathrm{LiMn}_{2} \mathrm{O}_{4}$

Hongming Zhou

zhouhongming@csu.edu.cn

1 School of Materials Science and Engineering, Central South University, Changsha 410083, Hunan, China

2 Hunan Zhengyuan Institute for Energy Storage Materials and Devices, Changsha 410083, Hunan, China or their mixtures [6-8]. At present, there are two main methods for recovery and reuse of cathode materials in spent $\mathrm{LiFePO}_{4} / \mathrm{C}$ batteries: physical recycling and hydrometallurgical recycling [3,9-12]. These two methods have their own merits, hydrometallurgical recovery processes can achieve high purity of lithium salts, iron salts and phosphates, physical recycling is facile and low cost. This work is dedicated to finding a green and efficient process to relieve the pressure on recycling so focus on the physical restoration.

The preparation of $\mathrm{LiFePO}_{4} / \mathrm{C}$ materials in physical recycling process in addition to increasing the proper $\mathrm{Li}, \mathrm{Fe}, \mathrm{P}, \mathrm{C}$ and other modifiers [13-18], a suitable sintering process is especially important. According to the principle of physical repairing materials, the general steps about physical repairing of spent $\mathrm{LiFePO}_{4} / \mathrm{C}$ materials: without destroying the original cladding layer and crystal structure of $\mathrm{LiFePO}_{4} / \mathrm{C}$, replenishing the missing elements and calcining under high temperature and cooling so that directly repairing the $\mathrm{LiFePO}_{4} / \mathrm{C}$ material. Similarly, the calcination temperature plays a crucial role in the synthesis of $\mathrm{LiFePO}_{4} / \mathrm{C}$ materials $[19,20]$. Studies have been reported that when the calcination temperature is higher than $800{ }^{\circ} \mathrm{C}, \mathrm{LiFePO}_{4}$ materials tend to decompose into impurities such as $\mathrm{LiFe}\left(\mathrm{P}_{2} \mathrm{O}_{7}\right), \mathrm{Fe}_{\mathrm{x}} \mathrm{P}$, $\mathrm{Li}_{3} \mathrm{PO}_{4}$ and $\mathrm{P}_{2} \mathrm{O}_{5}$. These impurities not only diminish the purity of the material, but also affect the electrochemical 
properties (such as reducing the specific capacity of the material, increasing self-discharge). It is disadvantageous for the formation and stability about the crystal structure of $\mathrm{LiFePO}_{4}$ when the calcination temperature is lower than $500{ }^{\circ} \mathrm{C}[21,22]$. Therefore, the synthesis temperature of the $\mathrm{LiFePO} / \mathrm{C}$ material is usually selected from 500 to $750{ }^{\circ} \mathrm{C}$. $\mathrm{Li}$ et al. [23] investigated direct regeneration procedure of recycled cathode material mixture from 600 to $800{ }^{\circ} \mathrm{C}$ with $\mathrm{Li}_{2} \mathrm{CO}_{3}$ and at $650{ }^{\circ} \mathrm{C}$ displayed excellent electrochemical performances. Chen et al. [24] also proved that cathode powders calcined at $650{ }^{\circ} \mathrm{C}$ displayed good electrochemical properties. Song et al. [25] investigated mechanochemical activation mechanisms and about $93.05 \% \mathrm{Fe}$ and $82.55 \%$ $\mathrm{Li}$ could be recovered as $\mathrm{FePO}_{4} \cdot 2 \mathrm{H}_{2} \mathrm{O}$ and $\mathrm{Li}_{3} \mathrm{PO}_{4}$ in the mechanochemical activation process. They all have detailed research on how calcination temperature repairs spent cathode material mixture, but the role played by calcination time is not discussed in detail.

In this paper, the spent cathode material mixture with $\mathrm{Li}_{2} \mathrm{CO}_{3}$ uniformly ball-milling for $6 \mathrm{~h}$ and calcining for different time at $700{ }^{\circ} \mathrm{C}$ after the element content analysis of $\mathrm{Li}, \mathrm{Fe}$ and $\mathrm{P}$. A facile and sustainable physical direct regeneration method was studied to repair spent $\mathrm{LiFePO}_{4} / \mathrm{C}$ without using acid, alkali solution or precipitant, alleviating the high cost of recycling. It could be an ideal of calcination process for spent $\mathrm{LiFePO}_{4} / \mathrm{C}$ materials due to facile device, less process and higher economic value. Surprisingly, the regenerated material as cathode assembled into a 18,650 battery exhibits superb cycle stability (124.35 mAh $\mathrm{g}^{-1}$ in the first cycle and maintains $103.12 \mathrm{mAh} \mathrm{g}^{-1}$ after 2000 cycles at $0.5 \mathrm{C}$ ). In addition, we investigate the crystal structure, morphology of the spent $\mathrm{LiFePO}_{4}$ material and regenerated samples. Therefore, the investigation of physical direct regeneration procedure of recycled cathode material mixtures is valuable for designing and developing advanced recycling process.

\section{Experimental}

\subsection{Cathode material regeneration}

Spent soft-pack $\mathrm{LiFePO}_{4} / \mathrm{C}$ batteries used in this work were from Zhengyuan Research Institute in Hunan Province. In a dry environment, using a pair of scissors to disassemble the batteries, removing the core package, and then separating the spent $\mathrm{LiFePO}_{4} / \mathrm{C}$ material from the core package. Washing three times by DMC solution, and drying it under $80^{\circ} \mathrm{C}$ for $12 \mathrm{~h}$. The separated cathode materials were smashed by a pulverizer, and the aluminum powder was filtered by a sifter to obtain the recovered cathode material mixture. The proportion of element composition in spent $\mathrm{LiFePO}_{4}$ materials detected by Inductively Coupled Plasma Optical Emission
Spectrometer (ICP-OES, Blue, Spectro) is shown in Table 1. Adding an appropriate amount of $\mathrm{Li}_{2} \mathrm{CO}_{3}$ as $\mathrm{Li}$ source to keep that the molar ratio of $\mathrm{Li}$ to $\mathrm{Fe}$ in the material was $1: 1$. The $\mathrm{Li}_{2} \mathrm{CO}_{3}$ and cathode material mixture ball milled uniformly and dried for $6 \mathrm{~h}$ (Fig. 1). Recycled cathode material mixtures were further directly regenerated at $700^{\circ} \mathrm{C}$ for $2 \mathrm{~h}$, $3 \mathrm{~h}, 4 \mathrm{~h}, 5 \mathrm{~h}$ labeled as $2 \mathrm{~h}$-RLFP, 3h-RLFP, 4h-RLFP and 5 h-RLFP respectively in high purity $\mathrm{N}_{2}$ atmosphere.

\subsection{Batteries assembly}

Regenerated cathode material mixture as active substance, poly (vinyl difluoride) (PVDF) as binder and conductive Super-P in N-methyl-2-pyrrolidinon (NMP) at a weight ratio of $8: 1: 1$. New button batteries were assembled in an argon-filled glove box (Mbraunlab Master130, Germany). Metallic lithium foils were used as counter electrodes and Celgard @ 2325 were used as separators. The electrolyte was $1 \mathrm{M} \mathrm{LiPF}_{6}$ dissolved in a mixture of dimethyl carbonate (DMC), diethyl carbonate (DEC) and ethylene carbonate (EC) (1:1:1 by weight).

\subsection{Compositional and structural characterization}

The elemental composition and concentration in spent/ regenerated materials were detected by ICP-OES (Blue, Spectro). Surface configuration and crystal structure of samples were characterized by scanning electron microscope (SEM, Tescan, MIRA 3 LMU), transmission electron microscopy (TEM, Tecnai G2 F20) and X-ray diffraction (XRD, Siemens D 500). The presence of carbon is characterized by Raman spectra (LabRAMHR800).

\subsection{Electrochemical test}

New button batteries were tested on a multi-channel battery test system (NEWARE). Galvanostatic discharging/charging cycling was performed at several different current densities between cutoff potentials of 2.0-3.8 V. Cyclic voltammetry (CV) at a scan rate of $0.2 \mathrm{mV} \mathrm{s}^{-1}$ and electrochemical impedance spectroscopy (EIS) in the frequency range of $10 \mathrm{mHz}$ to $1000 \mathrm{kHz}$ were tested on the $\mathrm{CH}$ instrument 660D electrochemical workstation.

Table 1 Chemical composition of Spent-LFP

\begin{tabular}{llllll}
\hline Element & $\mathrm{Li}$ & $\mathrm{Fe}$ & $\mathrm{P}$ & $\mathrm{Al}$ & $\mathrm{M}(\mathrm{Li}: \mathrm{Fe}: \mathrm{P})$ \\
\hline Spent-LFP (wt\%) & 4.31 & 35.12 & 20.87 & 0.53 & $0.97: 1: 1.06$ \\
\hline
\end{tabular}




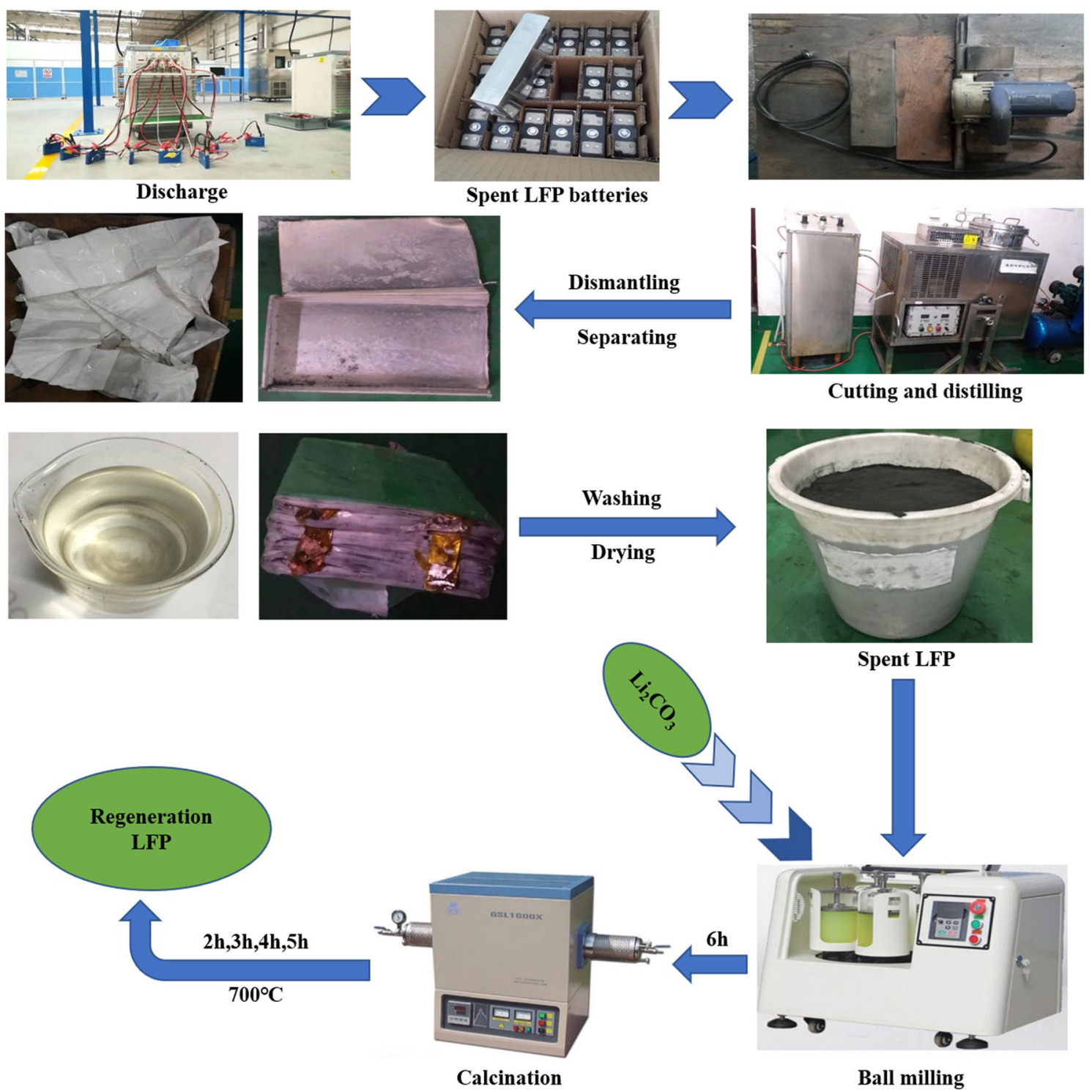

Fig. 1 The flow chart of recycling spent $\mathrm{LiFePO}_{4}$

\section{Results and discussion}

Figure 2 displays XRD pattern of $\mathrm{Li}_{2} \mathrm{CO}_{3}$ and spent $\mathrm{LiFePO}_{4}$ materials to examine their components and phase purity. The characteristic peaks from both spent LFP and $\mathrm{Li}_{2} \mathrm{CO}_{3}$ can be indexed to the crystal of LFP (JCPDS 83-2092) and $\mathrm{Li}_{2} \mathrm{CO}_{3}$ (87-0729), respectively. Compared with LFP (JCPDS 83-2092), spent LFP emerges three distinct peaks of impurities $\mathrm{FePO}_{4}, \mathrm{P}_{2} \mathrm{O}_{5}$ and $\mathrm{C}$ shown in Fig. 2a. The impurities of $\mathrm{FePO}_{4}$ and $\mathrm{P}_{2} \mathrm{O}_{5}$ are caused by the decomposition of some LFP particles [23]. Li sources commonly used for experiment are $\mathrm{LiOH}, \mathrm{Li}_{2} \mathrm{CO}_{3}, \mathrm{Li}_{2} \mathrm{C}_{2} \mathrm{O}_{4}, \mathrm{CH}_{3} \mathrm{COOLi}$ and $\mathrm{CH}_{3}\left(\mathrm{CH}_{2}\right)_{3} \mathrm{Li}$ and in this work using $\mathrm{Li}_{2} \mathrm{CO}_{3}$ to synthesize commercial LFP due to its low price. The XRD pattern of $\mathrm{Li}_{2} \mathrm{CO}_{3}$ corresponds to the diffraction peak in JCPDS:
87-0729 card shown in Fig. 2b which exhibits good crystallinity and high purity without impurity peak.

Figure 3 shows the XRD pattern of spent $\mathrm{LiFePO}_{4}$ material regenerated in calcination time of $2 \mathrm{~h}, 3 \mathrm{~h}, 4 \mathrm{~h}, 5 \mathrm{~h}$, respectively. Compared with the spent LFP material, the RLFPs have a lower $\mathrm{C}$ peak strength. When the calcination time is higher than $3 \mathrm{~h}$, the impurity phase $\mathrm{Li}_{3} \mathrm{PO}_{4}$ disappears and when the calcination time is higher than $5 \mathrm{~h}$, the $\mathrm{P}_{2} \mathrm{O}_{5}$ impure phase appears in the material and increases gradually because resynthesized $\mathrm{LiFePO}_{4}$ begins to decompose at high regeneration temperature. Therefore, we possess the higher purity RLFP materials when the calcination time is $3 \mathrm{~h}$ or $4 \mathrm{~h}$ (Fig. 3b). Figure 4 shows the Raman spectroscopy of $2 \mathrm{~h}$, $3 \mathrm{~h}, 4 \mathrm{~h}, 5 \mathrm{~h}-\mathrm{RLFP}$ to characterize the surface structure of the regeneration material. Two strong peaks distinctly appear in 

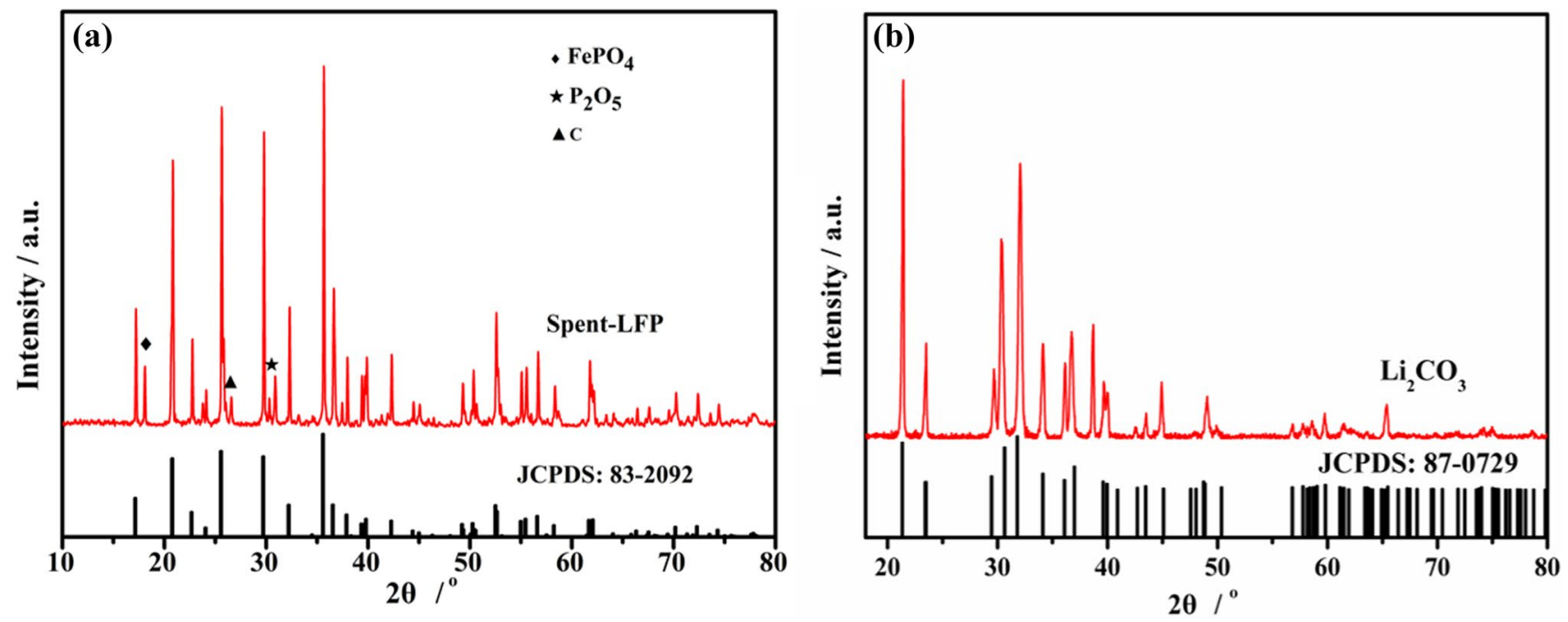

Fig. 2 XRD pattern of a Spent-LFP and $\mathbf{b} \mathrm{Li}_{2} \mathrm{CO}_{3}$
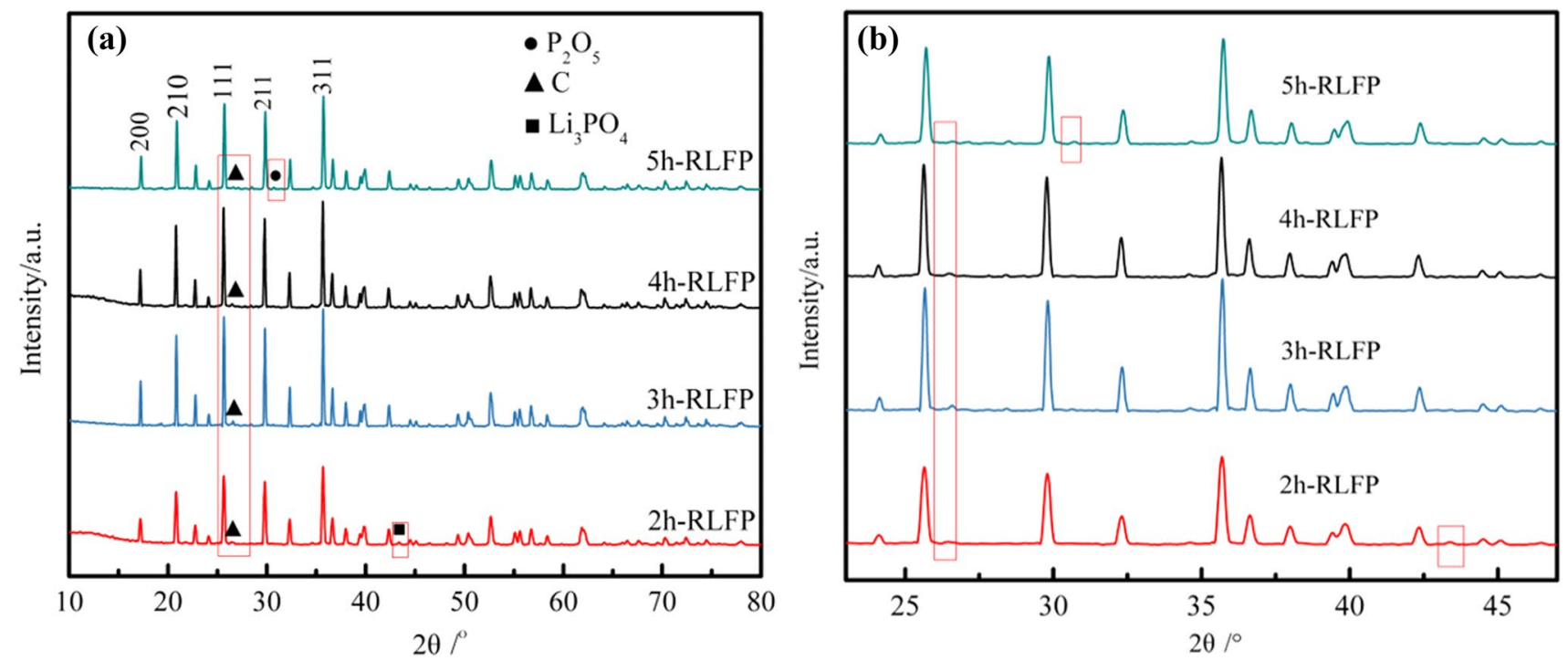

Fig. 3 a XRD patterns of $2 \mathrm{~h}, 3 \mathrm{~h}, 4 \mathrm{~h}, 5 \mathrm{~h}-\mathrm{RLFP}, \mathbf{b}$ is a local enlargement of $\mathbf{a}$

$1300-1600 \mathrm{~cm}^{-1}$, which correspond to the $\mathrm{D}$ and $\mathrm{G}$ peaks of carbon. By calculating the ratio of ID/IG, characterizing the ordering degree of carbon materials. When the calcination temperature is $3-5 \mathrm{~h}$, the ordering degree of the material's surface is identical corresponding to the ID/IG of 1.28, 1.10, 1.10 and 1.10 of $2 \mathrm{~h}, 3 \mathrm{~h}, 4 \mathrm{~h}, 5 \mathrm{~h}-\mathrm{RLFP}$ respectively, demonstrating high graphitization and ordering of the 3h-RLFP's surface.

The morphology and particle size of the spent-LFP, $2 \mathrm{~h}$, $3 \mathrm{~h}, 4 \mathrm{~h}$, 5h-RLFP were examined by SEM. As shown in Fig. 5, the particle size of the RLFP continues to increase with the calcination time extending but accompany some small broken particles. Figure 5a shows that serious agglomeration phenomenon and broken particles due to residual of
PVDF. With the decomposition of residual PVDF binder, the agglomeration phenomenon gets relieved or even disappear. Figure $5 \mathrm{~b}$ shows that the RLFP particles are not fully grown compared with the RLFP particles shown in Fig. 5c. In addition, the agglomeration of particles is more severe shown in Fig. 5d, e, revealing that the binder may decompose into a substance that is dispersed between the RLFP particle and $\mathrm{C}$ particle or among RLFP particles as the calcination time increases. Figure 5c exhibits a superior morphology and spherical RLFP particles with a diameter ranging from 1 to $2 \mu \mathrm{m}$.

TEM images are shown in Fig. 6 to further investigate the microstructure of the 3h-RLFP. PVDF as the binder turns into liquid so that wetting the RLFP particles in molten state 


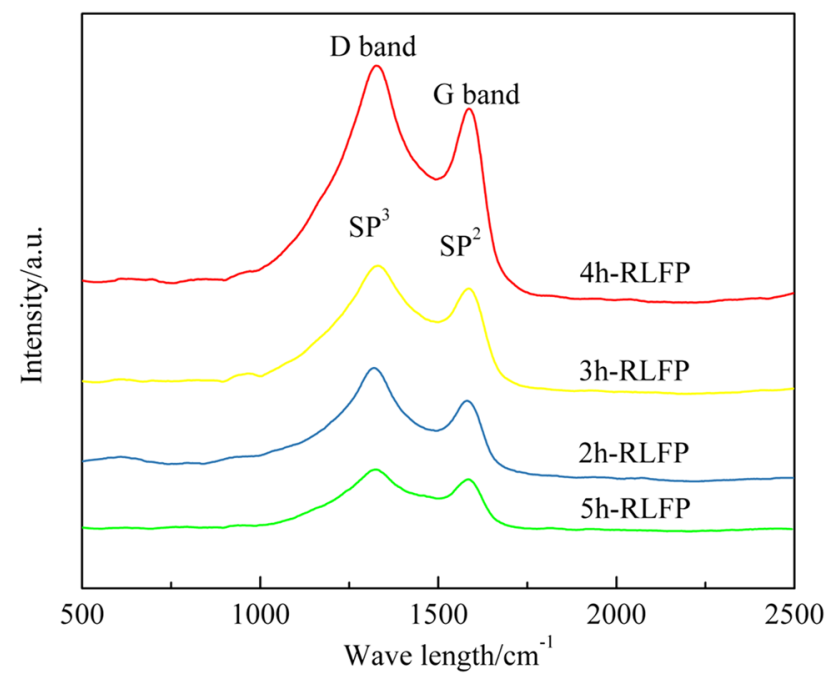

Fig. 4 Raman spectra of 2h, 3h, 4h, 5h-RLFP

by the capillary force after calcination. PVDF is decomposed into the amorphous carbon material as the reaction (1).

$\left[\mathrm{C}_{2} \mathrm{H}_{2} \mathrm{~F}_{2}\right]_{\mathrm{n}} \rightarrow \mathrm{nHF}($ gas $)+\mathrm{nC}$

As shown in Fig. 6a, the selected area reflects the severe structural disorder in spent-LFP particles noticeably. Those defects in the spent samples indicate that spent LFP particles suffer from lattice distortion and cracking during long-term charge and discharge cycling. Incomplete or broken LFP particles are caused by the generation of HF gas. And the amorphous carbon material converges among the RLFP particles for the conformation of a recognizable carbon layer (Fig. 6b). It can be observed from Fig. 6c, d that amorphous carbon materials co-coat the surface of intrinsic RLFP particles or conductive particles gradually, leading to nonuniform thickness of coated layers on the surface of RLFP particles. Figure $6 \mathrm{~d}$ exhibits unevenly coated layer on the part of the RLFP particle, indicating although the materials can be repaired at $700{ }^{\circ} \mathrm{C}$ for $3 \mathrm{~h}$, the generation of $\mathrm{HF}$ gas still causes unevenness of the coating. As the calcination time is prolonged, there still has amorphous carbon material deposited on the coating layer of the original carbon-coated RLFP particles and may result in a thicker coating layer shaping to hinder lithium ion insertion/extraction (Fig. 6e).

The charge-discharge curves of $2 \mathrm{~h}, 3 \mathrm{~h}, 4 \mathrm{~h}, 5 \mathrm{~h}$-RLFP materials at $0.2 \mathrm{C}$ rate in the voltage of $2.0-3.8 \mathrm{~V}$ are shown in Fig. 7a, which exhibits a relatively stable charge and discharge voltage platform with voltage differences. The charge and discharge curves of Spent-LFP display a morphology with large polarization, which reflects that spent $\mathrm{LiFePO}_{4}$ materials suffer severe structural defect during long-term utilization [3]. The electrochemical performance of the spent sample is revitalized again via simple physical regeneration assisted heat retreatment and extended regeneration
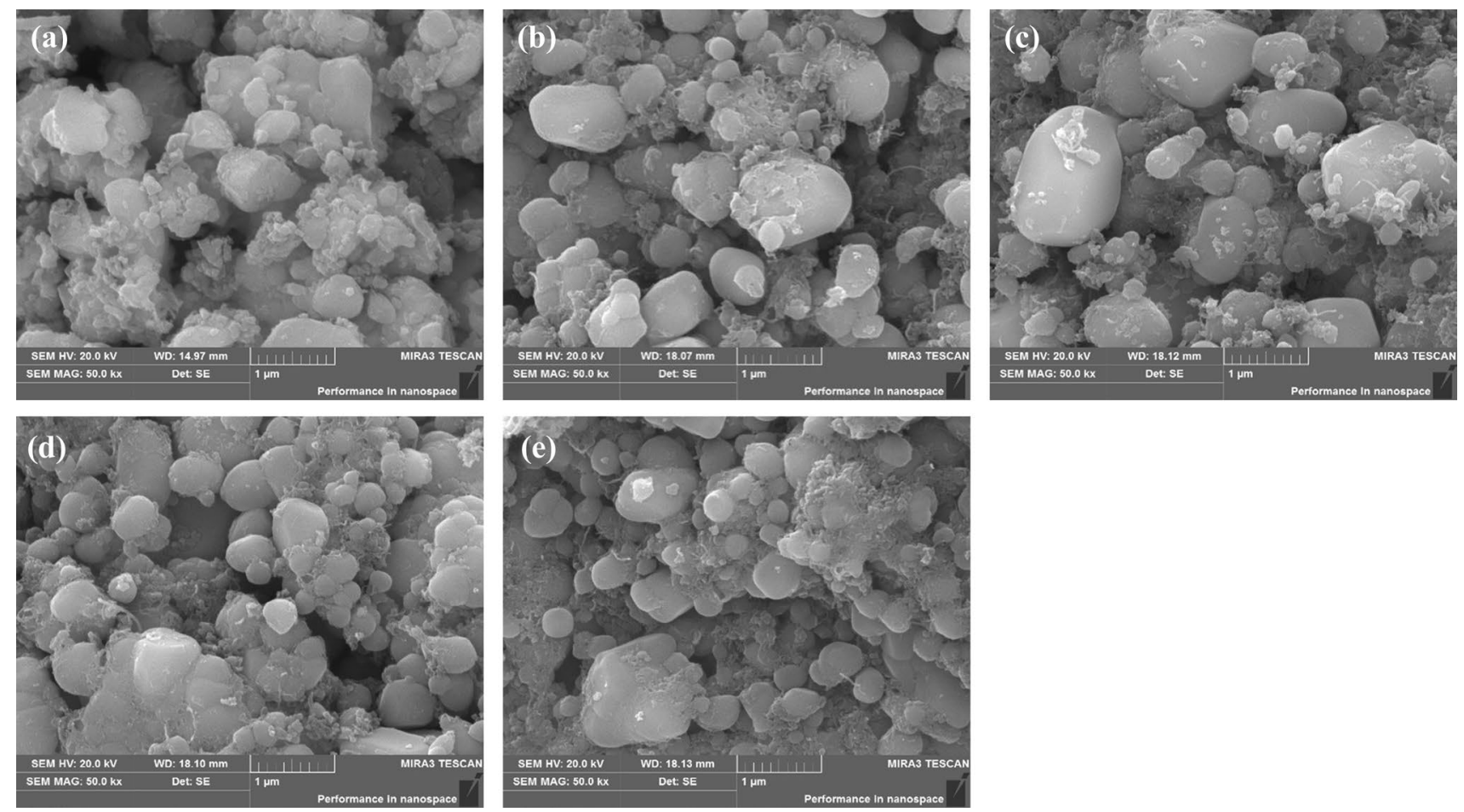

Fig. 5 SEM images of a Spent-LFP, b 2h-RLFP, $\mathbf{c}$ 3h-RLFP, $\mathbf{d}$ 4h-RLFP, e 5h-RLFP 
Fig. 6 TEM images of a SpentLFP, b-d 3h-RLFP at different resolutions, e Schematic illustration of PVDF decomposes as amorphous carbon in situ coated $\mathrm{LiFePO}_{4}$ particles for further lithium ions migration
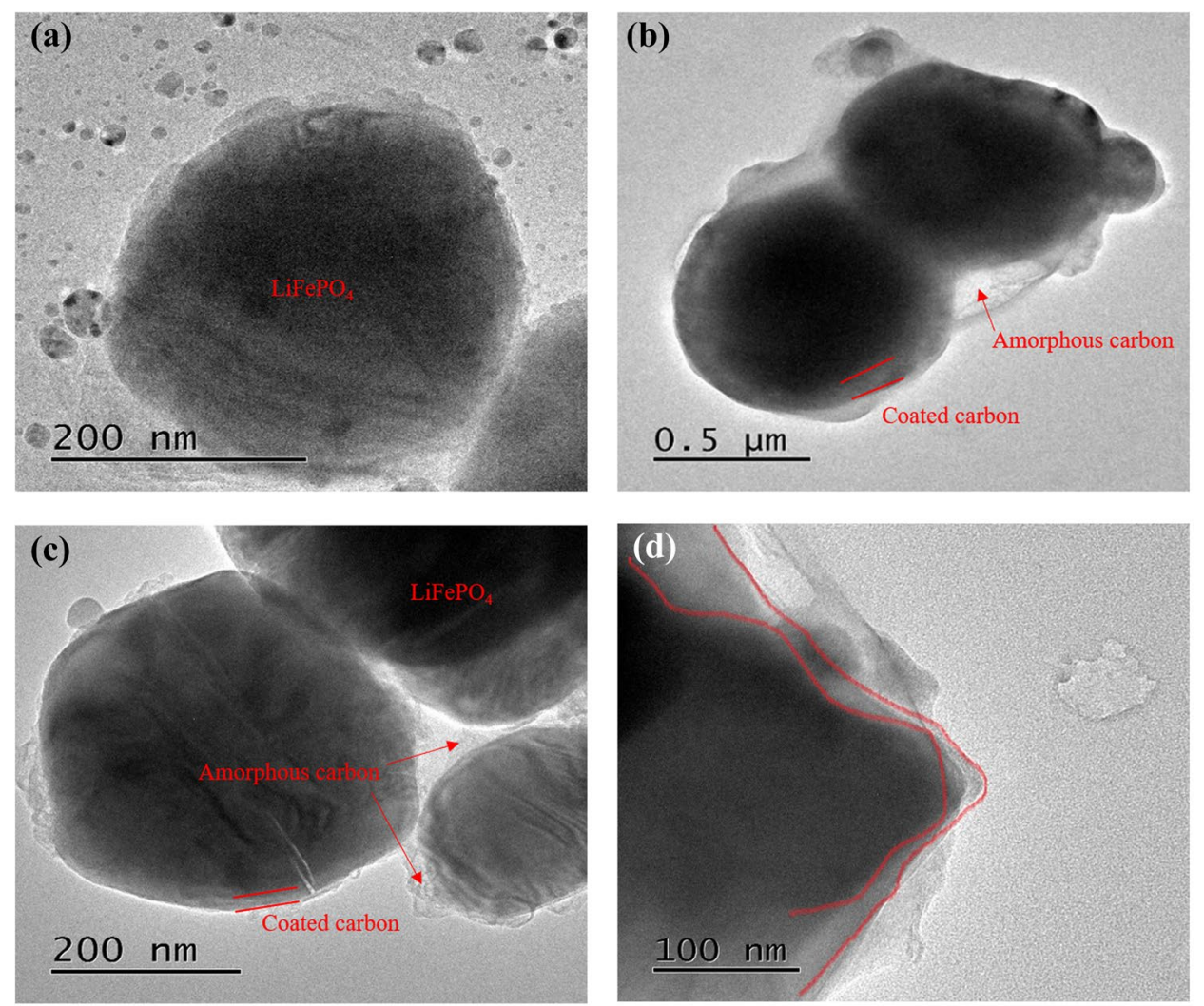

(e)

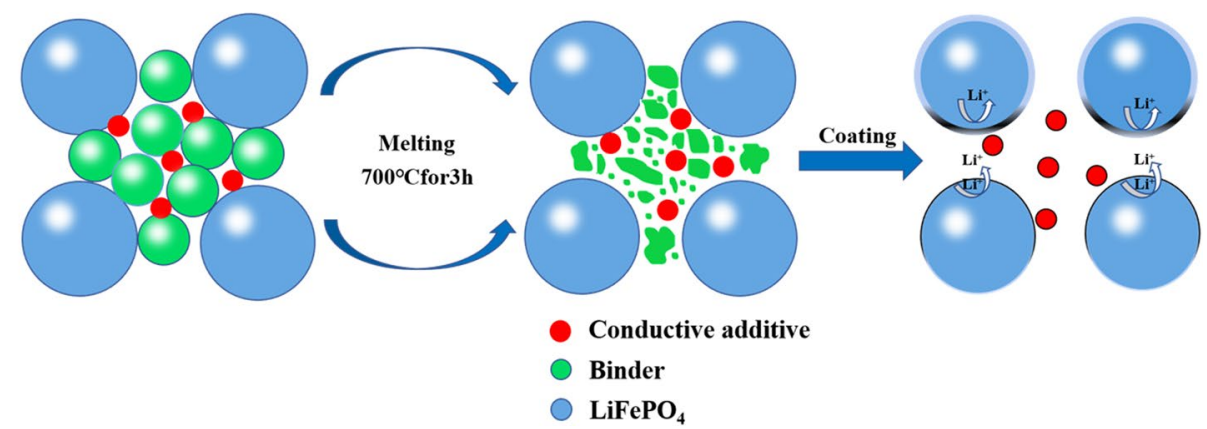

time. The corresponding discharge capacities of the investigated materials at $0.2 \mathrm{C}$ rate are $148.49,151.55,156.34$ and $154.79 \mathrm{mAh} \mathrm{g}^{-1}$, respectively. Among those cathode materials, 3h-RLFP delivers a charge capacity of $160.29 \mathrm{mAh} \mathrm{g}^{-1}$ and a discharge capacity of $151.55 \mathrm{mAh} \mathrm{g}^{-1}$ at $0.2 \mathrm{C}$ with a higher coulomb efficiency of $94.55 \%$. Figure $7 \mathrm{~b}$ shows the rate capabilities of $2 \mathrm{~h}, 3 \mathrm{~h}, 4 \mathrm{~h}$ and $5 \mathrm{~h}$-RLFP evaluated from 0.2 to $10 \mathrm{C}$ then back to $0.2 \mathrm{C}$ and five cycles are performed at a given rate, which is convenient in comparison of the discharge capacity for five simples. Compared with Spent LFP, the discharge capacity of RLFPs are greatly promoted at rates from 0.1 to $10 \mathrm{C}$. The $3 \mathrm{~h}-\mathrm{RLFP}$ displays a superior rate performance to the other RLFPs, with the discharge capacities of Spent-LFP, 2h-RLFP, 3h-RLFP, 4h-RLFP and 5h-RLFP presenting as 102.15, 129.22, 132.38, 130.28 and $124.95 \mathrm{mAh} \mathrm{g}^{-1}$ at the $5 \mathrm{C}$ rate and 97.5, 115.31, 120.44,
117.53 and $112.66 \mathrm{mAh} \mathrm{g}^{-1}$ at the $10 \mathrm{C}$ rate, respectively. These results collectively illustrate that physical direct regeneration for $3 \mathrm{~h}$ at $700{ }^{\circ} \mathrm{C}$ is the optimized condition for promoting the electrochemical performance of regenerated $\mathrm{LiFePO}_{4} / \mathrm{C}$ materials. The capacities of the five samples similar to their initial discharge capacities at the final cycle of $0.1 \mathrm{C}$ due to the good electrochemical reversibility and structural stability of phosphor-olivine $\mathrm{LiFePO}_{4}$. The 3h-RLFP exhibits superior cycling performance shown in Fig. 7c, which delivers a discharge capacity of $152.42 \mathrm{mAh}$ $\mathrm{g}^{-1}$ in the initial cycle and still remains $148.94 \mathrm{mAh} \mathrm{g}^{-1}$ with a high capacity retention rate of $97.71 \%$ at $0.5 \mathrm{C}$ after 200 cycles compared with Spent-LFP, 2h, 3h, 4h, 5h-RLFP (Table 2).

Figure 8 a illustrates the $\mathrm{CV}$ profiles of the $2 \mathrm{~h}, 3 \mathrm{~h}, 4 \mathrm{~h}$, $5 \mathrm{~h}$-RLFP electrodes at a scan rate of $0.2 \mathrm{mV} \mathrm{s}^{-1}$ between 

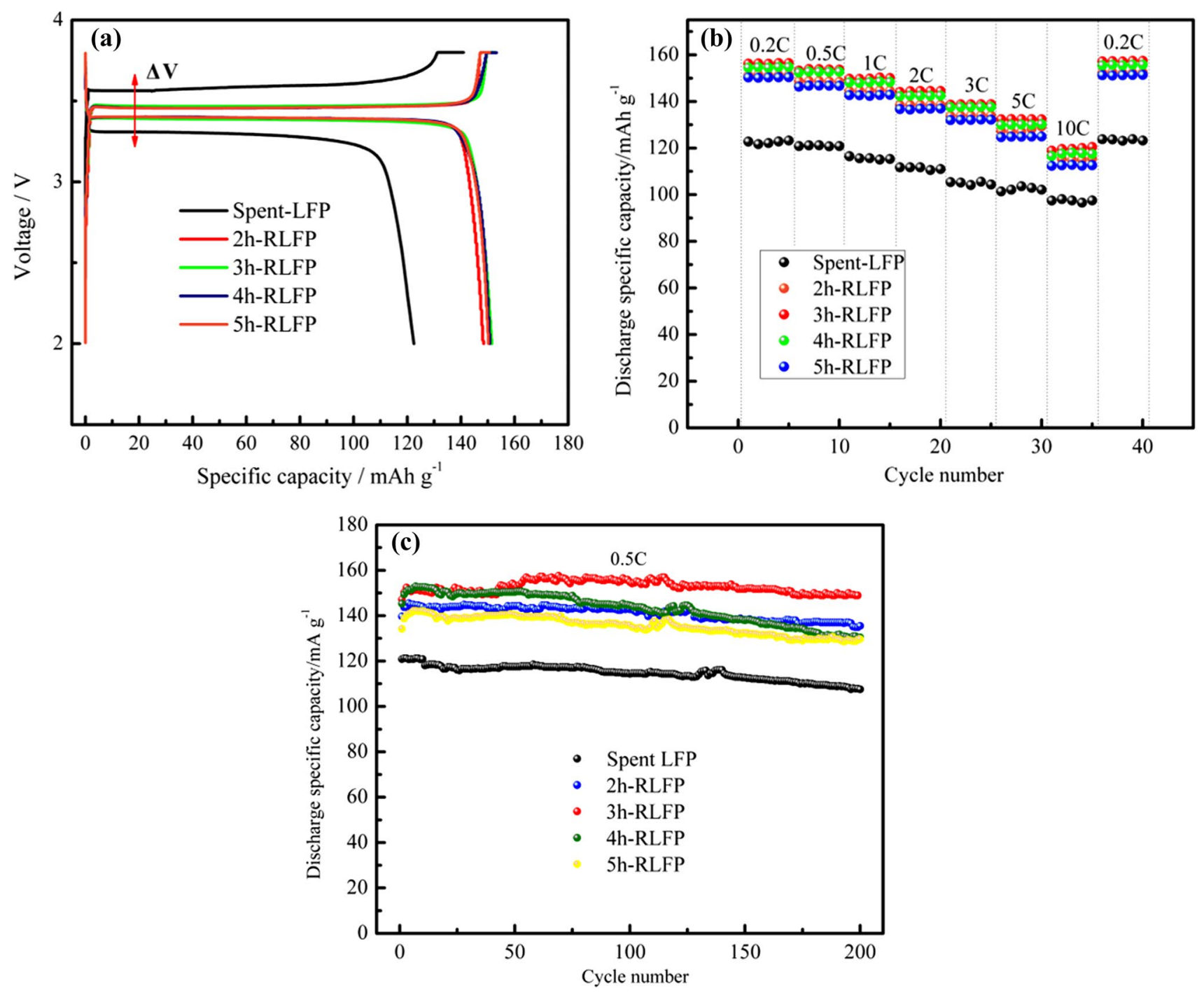

Fig. 7 a Charge-discharge curve of Spent-LFP, 2h, 3h, 4h, 5h-RLFP at $0.2 \mathrm{C}$ rate, b rate capabilities of Spent-LFP, 2h, 3h, 4h, 5h-RLFP in the voltage range of 2-3.8 V, cycling performance of Spent-LFP, $2 \mathrm{~h}, 3 \mathrm{~h}, 4 \mathrm{~h}, 5 \mathrm{~h}-\mathrm{RLFP}$ at $0.5 \mathrm{C}$ rate

Table 2 The discharge capacity and capacity retention rate of SpentLFP, 2h, 3h, 4h, 5h-RLFP

\begin{tabular}{llll}
\hline Electrode & $\begin{array}{l}\text { Capacity retention } \\
\text { rate }(\%)\end{array}$ & \multicolumn{2}{l}{$\begin{array}{l}\text { Discharge capacity } \\
\left(\mathrm{mAh} \mathrm{g}^{-1}\right)\end{array}$} \\
\cline { 3 - 4 } & & $1 \mathrm{st}$ & 200th \\
\hline Spent-LFP & 89.01 & 120.84 & 107.56 \\
2h-RLFP & 92.70 & 145.49 & 134.87 \\
3h-RLFP & 97.71 & 152.42 & 148.94 \\
4h-RLFP & 85.75 & 152.18 & 130.50 \\
5h-RLFP & 90.70 & 141.98 & 128.77 \\
\hline
\end{tabular}

2.0 and $4.5 \mathrm{~V}$ which shows a low polarization, symmetric and speculate peak, confirming an excellent reversibility for the RLFPs about lithium ion insertion and extraction. The oxidation-reduction peak voltage differences of $2 \mathrm{~h}$-RLFP, 3h-RLFP, 4h-RLFP and 5h-RLFP are 0.421, 0.353, 0.362 and $0.367 \mathrm{~V}$, respectively. Therefore, the voltage difference of redox peak is the smallest and the electrode polarization is minimum when using $3 \mathrm{~h}-\mathrm{RLFP}$ as cathode. The 3h-RLFP also possesses the largest current of the reduction peak $(\mathrm{I}=1.847 \mathrm{~mA})$ and the highest ionic conductivity of lithium ion.

Figure $8 \mathrm{~b}$ shows the fitting result of electrochemical impedance spectroscopy (EIS) and equivalent circuit diagrams of RLFP materials with the scanning frequency range from $10 \mathrm{mHz}$ to $1000 \mathrm{kHz}$. The high frequency region of the semicircle denotes charge transfer impedance and the sloped lines in the low frequency region is attributed to the Warburg impedance (W) associated with the solid-state Liions diffusion into the electrode materials [26]. $\mathrm{R}_{\mathrm{S}}$ refers to 


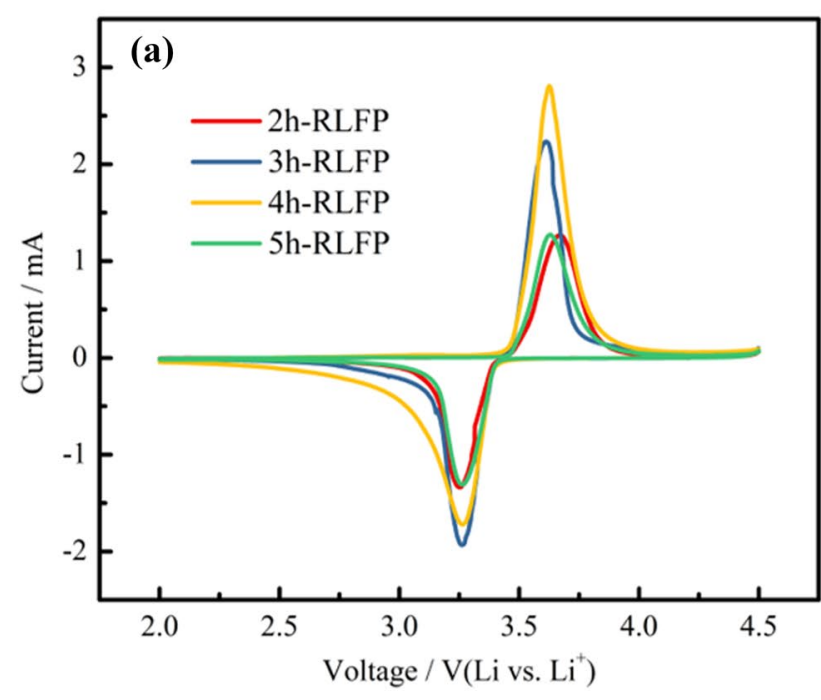

Fig. 8 a Cyclic voltammetry curves of $2 h, 3 h, 4 h, 5 h-R L F P$ in the voltage range of $2.0-4.5 \mathrm{~V}$ at the scan rate of $0.2 \mathrm{mV} \mathrm{s}^{-1}$, b electrochemical impedance spectra (EIS) curves of Spent-LFP, 2h, 3h, 4h,

Table 3 Fitting results of various electrodes based on equivalent electric circuit from Fig. 8b

\begin{tabular}{llr}
\hline Electrode & Rs $(\Omega)$ & Rct $(\Omega)$ \\
\hline Spent-LFP & 3.27 & 153.10 \\
2h-RLFP & 3.15 & 88.21 \\
3h-RLFP & 2.92 & 64.32 \\
4h-RLFP & 2.17 & 73.40 \\
5h-RLFP & 1.35 & 94.80 \\
\hline
\end{tabular}

the uncompensated resistance which might contains particle-particle contact resistance and the resistance between the electrode and the current collector [27]. Table 3 reveals the fitting results of each electrode based on the equivalent circuit in Fig. 8b. One semicircle and one straight line are observed in all regenerated cathode materials, indicating significantly reduced high film impedance [23]. Compare with Spent-LFP, the deteriorated particles internal structure corresponds to the increase of charge transfer impedance (Rct) of regenerated ones. And the 3h-RLFP material possesses slightly deteriorated structure compared to other regenerated samples. Because PVDF in cathode material decomposes to HF gas during high temperature regeneration procedure, which destroys $\mathrm{LiFePO}_{4}$ structure [23]. The changes of EIS curves show that $\mathrm{LiFePO}_{4}$ particles surface after regenerated reasonable time has been effectively repaired due to re-synthesis of $\mathrm{LiFePO}_{4}$. After regenerated for $2 \mathrm{~h}, \mathrm{HF}$ gas has been released a lot, leading to deteriorated structure and corresponding to a larger Rct. When regenerated than $3 \mathrm{~h}$, the Rct of regenerated ones increases, indicating that the decomposition of PVDF into carbon accumulates in the coating layer which gradually forms an excessively thick layer, thereby increases the lithium ions migration

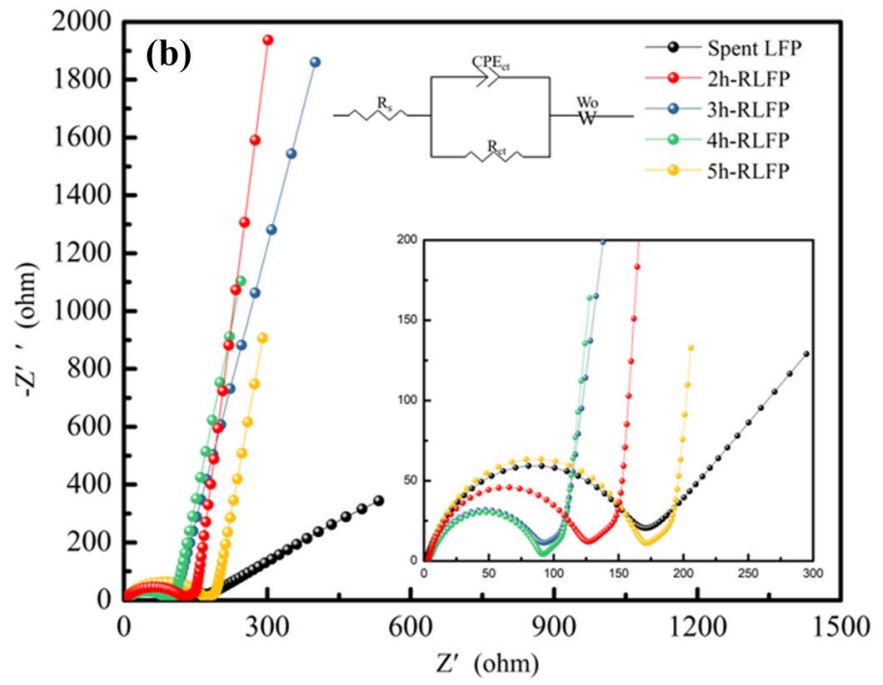

5h-RLFP in the frequency range from $10 \mathrm{mHz}$ to $1000 \mathrm{kHz}$ with corresponding equivalent circuit

resistance. From 2h-RLFP to 5h-RLFP, the Rs decreases because particles interior is gradually regenerated as the regeneration time increases.

Among those regenerated ones, $\mathrm{LiFePO}_{4}$ particles surface of $3 \mathrm{~h}$-RLFP is effectively regenerated because of favorable temperature and moderate time, leading to small Rct and excellent high rate performances at $10 \mathrm{C}$ (Fig. 7b). The charge transfer resistance of the 3h-RLFP is the smallest of $64.32 \Omega$ among those electrodes, indicating that the distinctive in situ carbon-coated structure effectively reduces the barrier for lithium ion transfer at the electrode-electrolyte interface.

18,650 battery was fabricated and tested with the $3 \mathrm{~h}$-RLFP as cathode and graphite as anode. Cycling capability of $3 \mathrm{~h}$-RLFP in the voltage range of $2.0-3.8 \mathrm{~V}$ at the rate of $0.5 \mathrm{C}$ during 18,650 battery discharging process is shown in Fig. 9. The 3h-RLFP possesses a superior cycling stability, which delivers a discharge capacity of $124.35 \mathrm{mAh}$ $\mathrm{g}^{-1}$ in the first and maintains $103.12 \mathrm{mAh} \mathrm{g}^{-1}$ with a high capacity retention rate of $82.93 \%$ after 2000 cycles at $0.5 \mathrm{C}$. The promising result brought by $3 \mathrm{~h}-\mathrm{RLFP}$ can be expected to be applied to the cathode of lithium-ion batteries.

\section{Conclusion}

A facile and sustainable physical-direct regeneration method was researched to recycle spent $\mathrm{LiFePO}_{4}$ batteries in this work. It is demonstrated that the 3h-RLFP not only possesses superb morphology but also has an enhanced electrochemical performance which shows the excellent discharge specific capacity of $151.55 \mathrm{mAh} \mathrm{g}^{-1}$ with a high capacity 


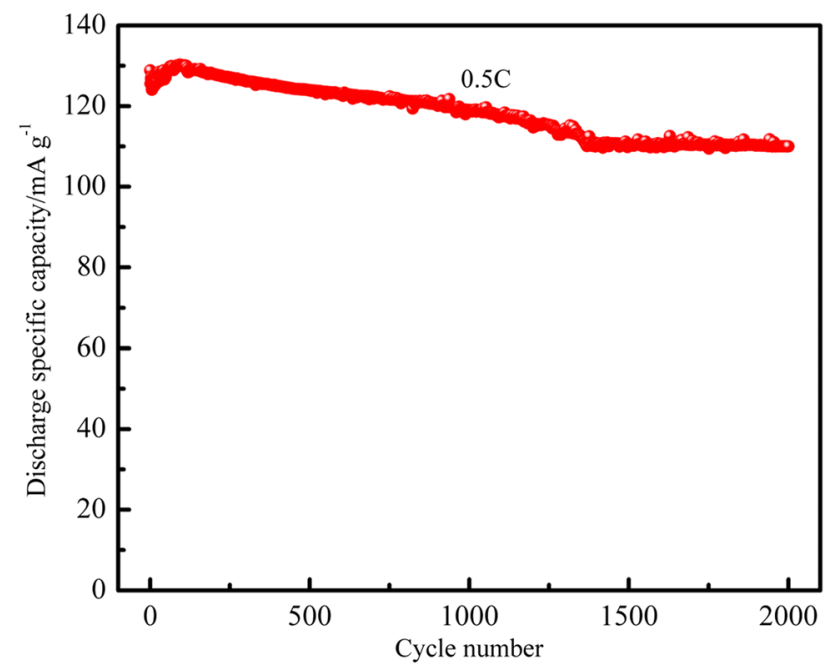

Fig. 9 Cycling performance of 3h-RLFP as cathode in the voltage range of $2.0-3.8 \mathrm{~V}$ at the rate of $0.5 \mathrm{C}$ by 18,650 battery discharge testing

retention rate of $97.77 \%$ at $0.2 \mathrm{C}$ rate. In addition, the in situ coated carbonaceous layer improves the conductivity and stimulates a better rate capability with a discharge capacity of $120.44 \mathrm{mAh} \mathrm{g}^{-1}$ at a relatively high rate of 10C compared with pristine spent LFP. 18,650 battery testing delivers a discharge capacity of $124.35 \mathrm{mAh} \mathrm{g}^{-1}$ in the first cycle and maintains $103.12 \mathrm{mAh} \mathrm{g}^{-1}$ with capacity retention rate of $82.93 \%$ after 2000 cycles at $0.5 \mathrm{C}$. Overall, the fabrication process of $3 \mathrm{~h}$-RLFP can be considered as a facile and largescale recycling method for lithium-ion batteries.

Acknowledgements This work was supported by the Natural Science Foundation of China (Grant No. 51371198) and the Natural Science Foundation of Hunan provincial (Grant No. 2017JJ2168).

Open Access This article is distributed under the terms of the Creative Commons Attribution 4.0 International License (http://creativeco mmons.org/licenses/by/4.0/), which permits unrestricted use, distribution, and reproduction in any medium, provided you give appropriate credit to the original author(s) and the source, provide a link to the Creative Commons license, and indicate if changes were made.
2. A.S. Aricò, P. Bruce, B. Scrosati, J.M. Tarascon, W.V. Schalkwijik, Nat. Mater. 4, 366-377 (2005)

3. D. Bian, Y. Sun, S. Li et al., Electrochim. Acta 190, 134-140 (2016)

4. G.Q. Cai, K.Y. Fung, K.M. Ng, Ind. Eng. Chem. Res. 53, 1824518259 (2014)

5. T. Georgi-Maschler, B. Friedrich, R. Weyhe, H. Heegn, M. Rutz, J. Power Sources 207, 173-182 (2012)

6. H.Y. Zou, E. Gratz, D. Apelian, Y. Wang, Green Chem. 15, 1183 1191 (2013)

7. T. Zhang, Y.Q. He, F.F. Wang, L.H. Ge, X.N. Zhu, H. Li, Waste Manag. 34, 1051-1058 (2014)

8. Y. Zhang, Y. Zhang, Y. Zhang et al., J. Alloys Compds. 783, 357-362 (2019)

9. X. Zhang, L. Li, E. Fan, Q. Xue, Y. Bian, F. Wu, R. Chen, Chem. Soc. Rev. 47(19), 7239-7302 (2018)

10. L. Yang, G. Xi, Y. Xi, Ceram. Int. 41, 11498-11503 (2015)

11. Q. Sa, E. Gratz, M. He, W. Lu, D. Apelian, Y. Wang, J. Power Sources 282, 140-145 (2015)

12. P. Meshram, B.D. Pandey, T.R. Mankhand, Chem. Eng. J. 281, 418-427 (2015)

13. R. Gupta, S. Saha, M. Tomar, V.K. Sachdev, V. Gupta, J. Mater. Sci.: Mater. Electron. 28(7), 5192-5199 (2017)

14. S.Y. Chung, Y.M. Chiang, Electrochem. Solid-State Lett. 6(12), A278-A281 (2003)

15. X. Hui, Z. Zhou, Electrochim. Acta 51(10), 2063-2067 (2006)

16. C.Y. Chiang, H.C. Su, P.J. Wu, H.J. Liu, C.W. Hu, N. Sharma et al., J. Phys. Chem. C 116(46), 24424-24429 (2012)

17. H. Liu, Q. Cao, L.J. Fu, C. Li, Y.P. Wu, H.Q. Wu, Electrochem. Commun. 8(10), 1553-1557 (2006)

18. J.F. Ni, H.H. Zhou, J.T. Chen, X.X. Zhang, Mater. Lett. 59(18), 2361-2365 (2005)

19. F. Feng, R. Lu, C. Zhu, Energies 7(5), 3004 (2014)

20. Y. Xing, W. He, M. Pecht, K.L. Tsui, Appl. Energy 113, 106-115 (2014)

21. F. Feng, R. Lu, G. Wei, C. Zhu, Energies 8(4), 2950 (2015)

22. C. Fleischer, W. Waag, H.-M. Heyn, D.U. Sauer, J. Power Sources 262, 457-482 (2014)

23. X. Li, J. Zhang, D. Song et al., J. Power Sources 345, 78-84 (2017)

24. J. Chen, Q. Li, J. Song et al., Green Chem. 18, 2500-2506 (2016)

25. Y. Yang, X. Zheng, H. Cao et al., ACS Sustain. Chem. Eng. 5, 9972-9980 (2017)

26. L. Li, A.O. Raji, J.M. Tour, Adv. Mater. 43, 6298-6302 (2013)

27. S. Yoon, C. Liao, X.-G. Sun, C.A. Bridges, R.R. Unocic, J. Nanda et al., J. Mater. Chem. 22(11), 4611 (2012)

Publisher's Note Springer Nature remains neutral with regard to jurisdictional claims in published maps and institutional affiliations.

\section{References}

1. C.W. Sun, S. Rajasekhara, J.B. Goodenough, F. Zhou, J. Am. Chem. Soc. 133, 2132-2135 (2011) 